\title{
Sleep Disorder and Sleep Behavior Pattern in Children- A Survey
}

\author{
Gayathri Karthikeyan ${ }^{1}$ and Deepa Gurunathan ${ }^{2}$ \\ ${ }^{1}$ Saveetha Dental College and Hospitals Saveetha Institute of \\ Medical and Technical Sciences (SIMATS) Chennai, India \\ ${ }^{2}$ Professor Department of Pediatric and Preventive dentistry Saveetha Dental College and \\ Hospitals Saveetha Institute of Medical and Technical Sciences (SIMATS) Chennai, India
}

\begin{abstract}
Children spend one-third to one-half of their life sleeping. Although sleep occupies such a significant portion of a child's day, sleep disturbances are often overlooked by healthcare practitioners. Studies indicate that sleep problems in children and adolescents are highly prevalent, with prevalence rates ranging from 25\%to 40\%, and they are often persistent. The questionnaire-based study was carried out among 140. Parents with children between the ages of 6-10. The questionnaire comprised 20 questions which were used to detect the sleep behavior pattern and sleep disorders. The questionnaire was prepared and uploaded on to an online survey platform (surveyplanet) and the link was shared to the parents.The responses from the questionnaire included 68 males and 72 females. The most common age group was found to be between the ages of 6-10 years. Bed wetting occurred in about $17.9 \%$ of the cases. 15\% of the cases snored regularly. In addition, other sleep related disorders, such as sleep walking, sleep terror, bruxism were also frequent, occurring in 6.4, 7.9\%, 19.3\%, respectively. When finding the relationship between snoring and children talking in their sleep, we obtained a p-value of 0.013 which was statistically significant. The most common sleep disorder that was observed in this population was sleep talking which was about $25.7 \%$ of the people. There was no significant correlation between children with medical issues and children who woke up during their sleep at night. When finding the relationship between bedwetting and sleepwalking we obtained a $\mathrm{p}$ value of 0.030 which was statistically significant. When finding the relationship between the use of security objects and that of night terrors we obtained a p value of 0.00 which was highly significant. Sleeping disorders are highly prevalent in children and adolescents especially those who have undergone a psychological trauma. Early diagnosis and prompt treatment are necessary for the wellbeing of the child affected.
\end{abstract}

KEY WORDS: SLEEP DISORDER, CHILDREN, ADOLESCENTS, NIGHT, SLEEP WALKING.

\section{ARTICLE INFORMATION}

*Corresponding Author: drgdeepa@yahoo.co.in

Received 10th June 2020 Accepted after revision 7th August 2020

Print ISSN: 0974-6455 Online ISSN: 2321-4007 CODEN: BBRCBA

Thomson Reuters ISI Web of Science Clarivate Analytics USA and Crossref Indexed Journal

$$
1 \text { Clarivate }{ }_{\text {Analytics }} \text { crossef }
$$

NAAS Journal Score 2020 (4.31) SJIF: 2020 (7.728)

A Society of Science and Nature Publication,

Bhopal India 2020. All rights reserved.

Online Contents Available at: http//www.bbrc.in/

Doi: $h$ ttp://dx.doi.org/10.21786/bbrc/13.7/39 


\section{INTRODUCTION}

Sleep is the time period during which the body conserves energy, restore its normal processes, promote physical growth, and support mental development. These processes are very important during the growth of a child and hence children spend one-third to one-half of their life sleeping. Although sleep occupies such a significant portion of a child's day, sleep disturbances are often overlooked by healthcare practitioners. Studies, however, indicate that sleep problems in children and adolescents are highly prevalent, with prevalence rates ranging from 25\% $40 \%$, and they are often persistent (Owens, 2005) (Mindell and Owens, 2015).

Sleep disorders are mainly divided into dyssomnias, parasomnias and circadian rhythm sleep disorders. Dysomnias are the broad classification characterized by difficulty in getting sleep, remain sleep or excessive sleepiness. Parasomnias involve abnormal movements, behaviors, emotions, perceptions, and dreams that occur while falling asleep, sleeping, between sleep stages, or during arousal from sleep and Circadian rhythm sleep disorders (CRSD), is a family of sleep disorders, which affects (among other bodily processes) the timing of sleep and people affected by CRSD are unable to go to sleep and wake up at the times commonly required such as social needs(i.e waking up to school or going to work) Inadequate sleep quantity and quality have been associated with poor school performance, mental health problems, poor sociability, behavioral problems, the development of obesity and its accompanying comorbidities .(Gokul, 2016) ((Kim and Kim, 1998)

There are short- and long-term effects on life in sleep deprivation. The short-term effects include poor attention and concentration, reduced quality of life, low productivity and an increased absence in class or work, while long-term effects include higher morbidity and mortality due to car accidents, coronary artery disease, heart failure, hypertension, obesity, type-2 diabetes, stroke, depression, memory loss, and decreased immune function (Seo et al., 2008).According to a recent study conducted the prevalence of sleep-related diseases in children and adolescents was determined to be approximately $43 \%$, the rate of insomnia was determined to be $5 \%-20 \%$, the rate of obstructive sleep apnea was determined to be $1 \%-3 \%$, the frequency of snoring was determined to be $5 \%-27 \%$, and the rate of parasomnias was determined to be 14\%-37\% (Cho et al., 2002) (Chokroverty, 2010) (Jochebed and Priya, 2015).

Our department is passionate about child care, we have published numerous high quality articles in this domain over the past 3 years (Govindaraju, Jeevanandan and Subramanian, 2017a, 2017b; Panchal, Gurunathan and Shanmugaavel, 2017; Ravikumar, Jeevanandan and Subramanian, 2017; Jeevanandan and Govindaraju, 2018; Nair et al., 2018; Ravikumar et al., 2018, 2019; Ravindra et al., 2018, 2019; Subramanyam et al., 2018; Vishnu Prasad et al., 2018; Jeevanandan, Ganesh and Arthilakshmi, 2019; Ramadurai et al., 2019;
Ramakrishnan, Dhanalakshmi and Subramanian, 2019; Veerale Panchal, Jeevanandan and Subramanian, 2019; Vignesh et al., 2019; V. Panchal, Jeevanandan and Subramanian, 2019; Samuel, Acharya and Rao, 2020). With this inspiration we planned to pursue research on the sleep behavior pattern and sleep disorder in children .

\section{MATERIAL AND METHODS}

The questionnaire-based study was carried out among Parents with children between the ages of 6-10. The questionnaire comprised 20 questions which were used to detect the sleep behavior pattern and sleep disorders. The questionnaire was prepared and approved by the scientific review board of the institution. The questionnaire was uploaded on to an online survey platform (survey planet) and the link was shared to the parents. The questionnaire was just a screening questionnaire and cannot be used for diagnostic purposes.

Part 1 of the questionnaire was developed to include questions about the child's age and sex and if the child suffers from any medical problems.

Part 2 of the questionnaire was developed to include questions about how long the child takes to fall asleep, if the child experiences any trouble going to bed or falling asleep and does the child have any bedtime rituals. These questions were asked to assess the sleep behavior pattern of the child.

Part 3 of the questionnaire was concerned with the previously mentioned sleep disorder which were explicitly expressed in lay language.

Based on the responses from the subjects, the statistics was done and the results was obtained in a systematic manner. The statistics was carried out using the IMB SPSS software.

Figure 1: Pie chart shows the distribution of children that were considered for the survey, where blue represents female and green represents male. The most common gender noticed in the survey conducted were females

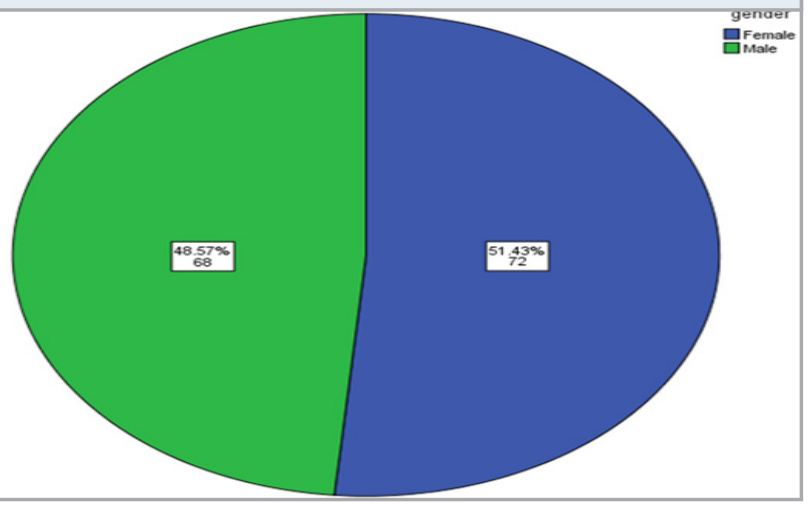

RESULTS AND DISCUSSION

Demographic Characteristics 140 responses were 
obtained which included 48.57\% males and 51.43\% females participants (Figure 1). Analysis of sleep behavior pattern shows that the most common response to the question how long does it takes for the child to fall asleep was between 5- 10 minutes (33.57\%) (Figure 2). Most children did not have any trouble going to bed or any trouble falling asleep. When asked if the children had any bedtime rituals the most common response was no and even if they did the most common among them was saying a prayer before going to bed.

Figure $2:$ Bar graph shows the distribution of time take by children to fall asleep (X-axis represents the time take for the children to fall asleep, Y-axis represents the number of children) where blue represents the time range between 0-2 $\min (5.71 \%)$, green represents time range between 2-5 $\min (15 \%)$, blue represents time range between 5-10 $\min (33.57 \%)$, purple represents time range between $10-15 \mathrm{~min}(10 \%)$, yellow represents time range between 15-20 $\min (10.71 \%)$, red represents time range between time range between $20-30 \mathrm{~min}(14.29 \%)$ and orange represents time range between $30-60 \mathrm{~min}(10.71 \%)$. The most common time range for children to fall asleep was between 5-10 $\mathrm{min}$

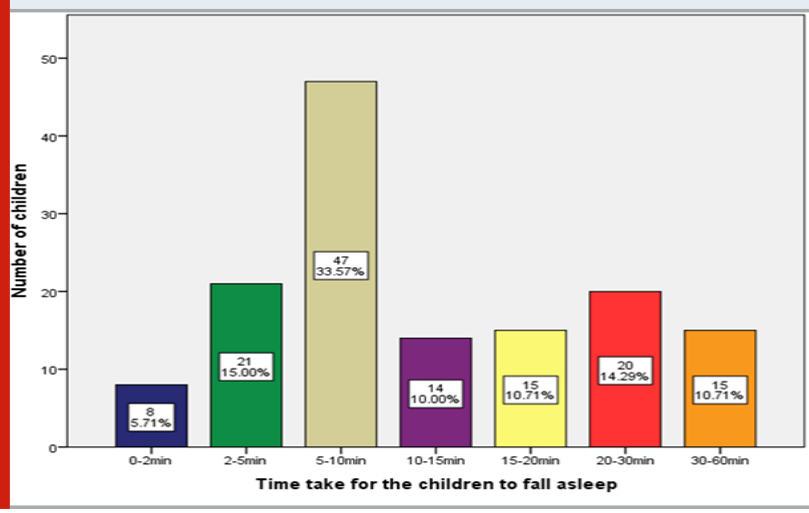

Figure 3: Pie chart shows the distribution of the response to the question, Does your child have the tendency to talk during their sleep. Blue represents the children who did not have the tendency to snore and green represents the children who had the tendency to snore. It was noted that about $25.72 \%$ of the children had the tendency of talking during their sleep

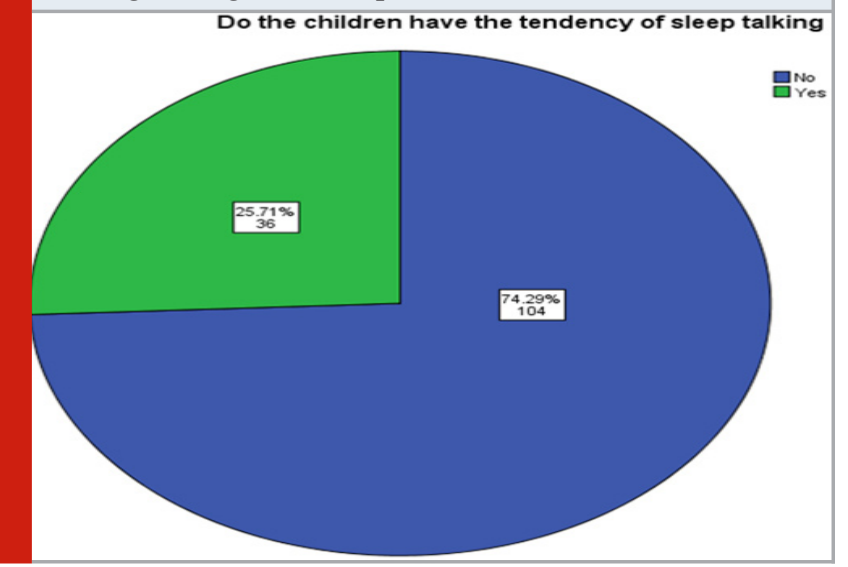

Analysis of sleep disorder: The most common sleeping disorder that was observed was sleep talking which included about 25.7\% responding yes to the question, does your child have the tendency to talk during their sleep (Figure 3). Bedwetting occurred in about 17.9\% of the cases (Figure 4) 15\% of the cases snored regularly. (Figure 5).

Figure 4: Pie chart shows the distribution of the response to the question, Does your child have the tendency of bed wetting. Blue represents the children who did not have the tendency of bedwetting during their sleep and green represents the children who had the tendency of bedwetting during their sleep. It was noted that about $17.86 \%$ of the children had the tendency of bedwetting during their sleep

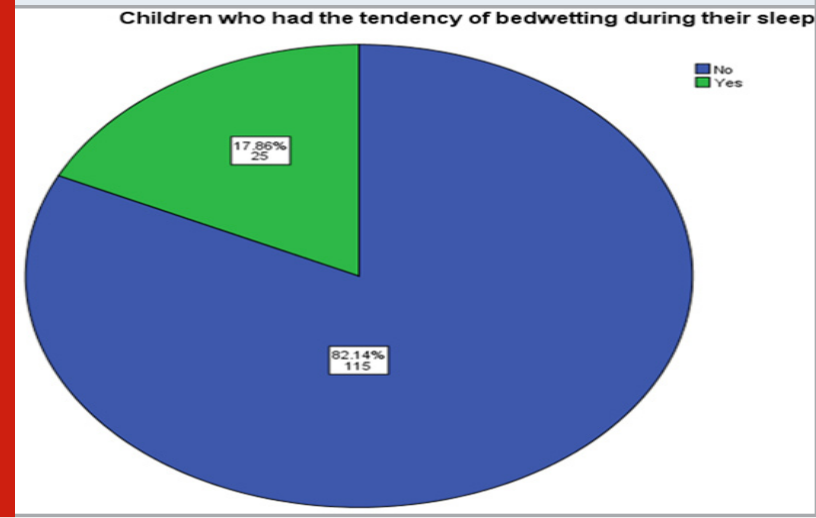

Figure 5: Pie chart shows the distribution of the response to the question, Does your child snore. Blue represents the children who did not have the tendency of snoring during their sleep and green represents the children who had the tendency of snoring during their sleep . It was noted that about 15\% of the children had the tendency of snoring during their sleep

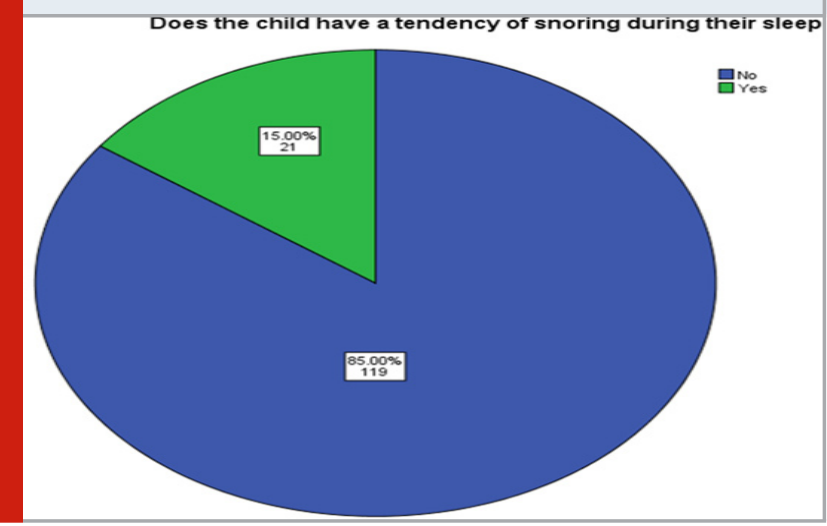

In addition, other sleep related disorders, such as sleep walking, night terror, teeth grinding occurring in 6.4(Figure 6), 7.9\% (Figure 7) , 19.3\%(Figure 8), people respectively. When finding the relationship between snoring and children talking in their sleep, we obtained a p-value of 0.013 which was statistically significant (Figure 9). There was no significant correlation between children with medical issues and children who woke up 
during their sleep at night with a p-value of 0.114 (Figure 10). When finding the relationship between bedwetting and sleepwalking we obtained a p-value of 0.724 which was not statistically significant ( Figure 11). When finding the relationship between the use of security object and that of night terrors we obtained a p- value of 0.00 which was highly significant (Figure 12).

Figure 6: Pie chart shows the distribution of the response to the question, Does your child have the tendency of sleepwalking . Blue represents the children who did not have the tendency of sleepwalking and green represents the children who had the tendency of sleepwalking. It was noted that about $6.4 \%$ of the children had the tendency of sleepwalking.

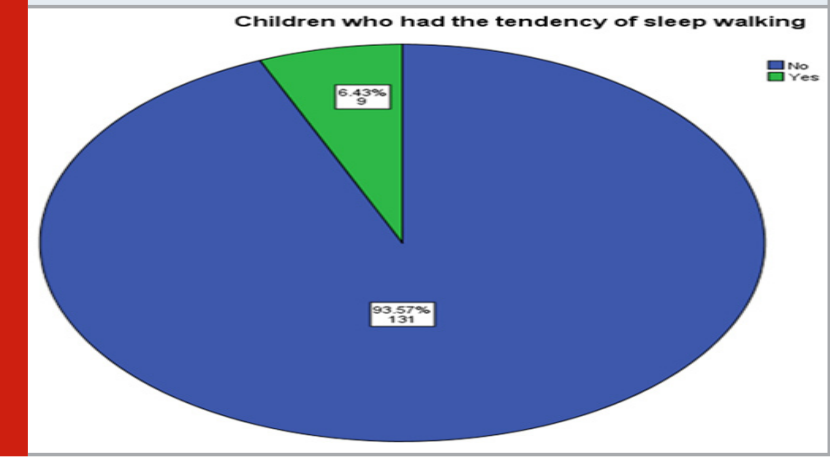

Figure 7: Pie chart shows the distribution of the response to the question, Is your child prone to night terrors (Episodes of screaming, intense fear and flailing while still asleep). Blue represents the children who did not have night terrors during their sleep and green represents the children who had night terrors during their sleep. It was noted that about $7.9 \%$ of the children had night terrors during their sleep.

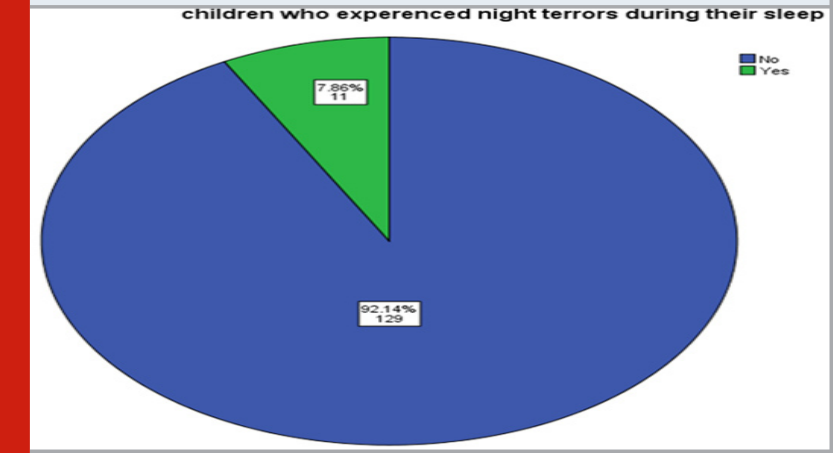

Although there are around 90 distinct sleep disorders, according to the International Classification of Sleep Disorders (Bhate and Williams, 2013) most are marked by one of these symptoms: excessive daytime sleepiness, difficulty initiating or maintaining sleep, or abnormal movements, behaviors, and sensations occurring during sleep. The cumulative effects of sleep loss and sleep disorders have been associated with a wide range of deleterious health consequences including an increased risk of hypertension, diabetes, obesity, depression, heart attack, and stroke. Lack of sleep can contribute to acne and other skin problem (Krakowski, Eichenfield and Dohil, 2008) (Kamphuis et al., 2012). Low sleeping hours can also lead to aggressive behavior resulting in harsh behavior with friends and family (Durmer and Dinges, 2005) The main symptom of sleep loss is excessive daytime sleepiness, but other symptoms include depressed mood and poor memory or concentration (Owens et al., 2000).

Figure 8: Pie chart shows the distribution of the response to the question, Does your child have the habit of grinding their teeth during their sleep ?. Blue represents the children who did not have the tendency of grinding their teeth during their sleep and green represents the children who had the tendency of grinding their teeth during their sleep. It was noted that about $19.29 \%$ of the children had the tendency of grinding their teeth during their sleep.

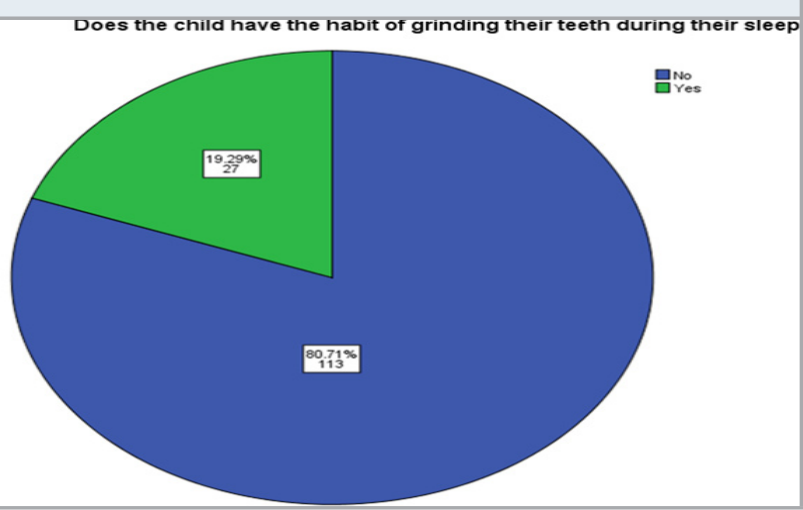

Figure 9: Bar graph shows the correlation between the response to children to snore and the children who talk during their sleep(X-axis shows the distribution of response to children to snore, Y-axis shows the distribution of response to children who talk during their sleep). Chisquare test was done and the association was not found to be statistically significant. Peason's value:6.206, DF:1, P value: $0.013(<0.05)$ hence statistically significant, proving that children who snore did have the tendency of talking during their sleep.

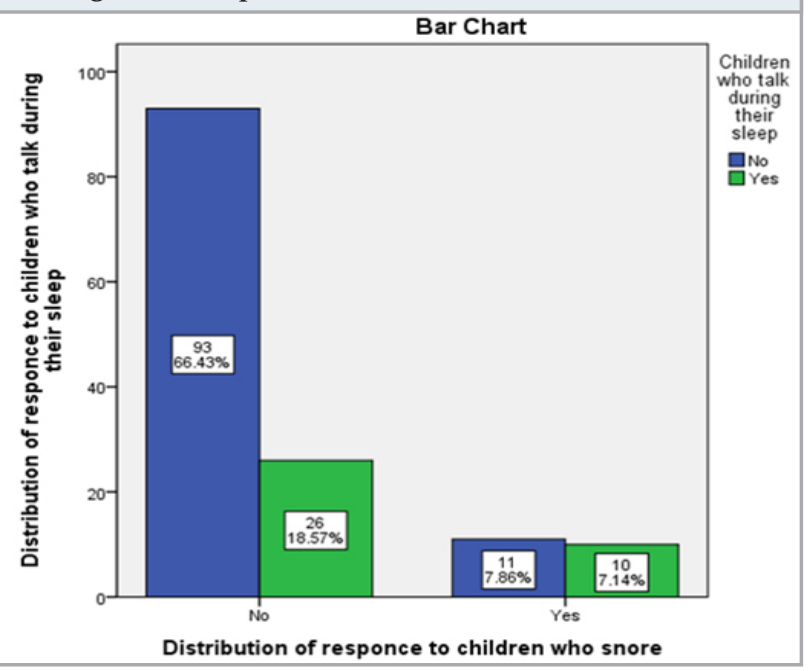


Figure 10: Bar graph shows the correlation between the response to whether children had any medical issue and the whether children woke up during the nigh (X-axis shows the distribution of response whether children had any medical issue, Y-axis shows the distribution of response whether children woke up during the night). Chisquare test was done and the association was not found to be statistically significant. Peason's value:2.493, DF:1, $P$ value: $0.114(>0.05)$ hence statistically not significant, proving that there is no association present between children who have medical issues and children who wake up during the night.

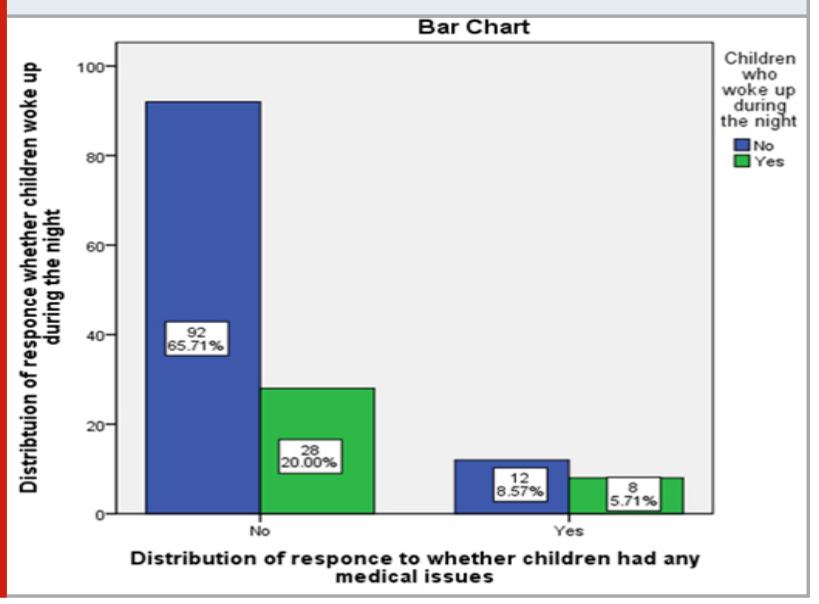
medical issues

Figure 11: Bar graph shows the correlation between the response to whether children who had the tendency of bedwetting and the whether children who had the tendency of sleepwalking (X-axis shows the distribution of response whether children had the tendency of bedwetting, Y-axis shows the distribution of response whether to whether children had the tendency of sleepwalking). Chi-square test was done and the association was not found to be statistically significant. Peason's value:0.125, DF:1, P value: $0.724(>0.05)$ hence statistically not significant, proving that there is no association present between children who have had the tendency of bedwetting and children who had the tendency of sleepwalking.

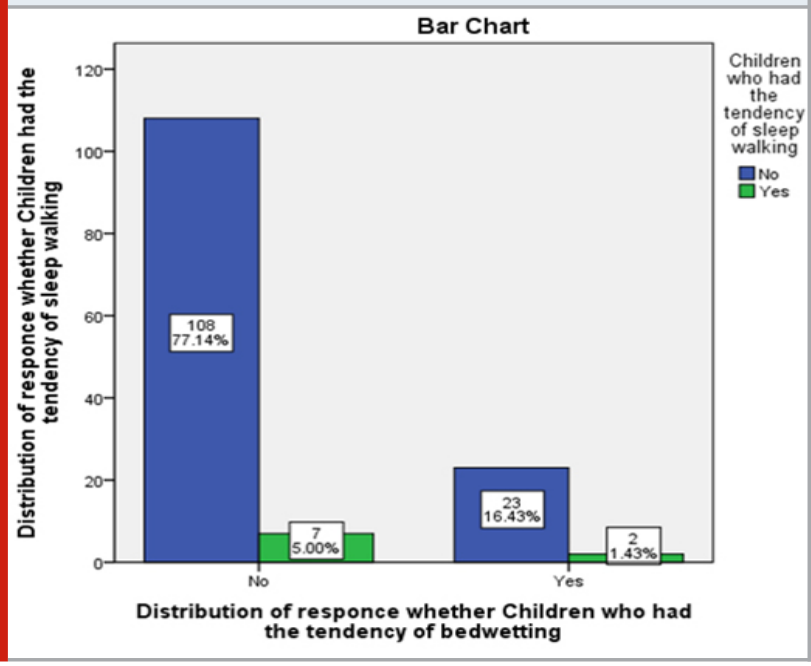

Figure 12: Bar graph shows the correlation between the response to whether children who had the tendency of using security object during their sleep and the whether children who experienced night terrors during their sleep (X-axis shows the distribution of response to whether children used security object while sleeping, Y-axis shows the distribution of response whether to whether experienced night terrors during their sleep). Chi-square test was done and the association was found to be statistically significant. Peason's value: $35.616, \mathrm{DF}: 1, \mathrm{P}$ value: $0.00(>0.05)$ hence statistically significant, proving that there children who experienced night terrors went to sleep with a security object

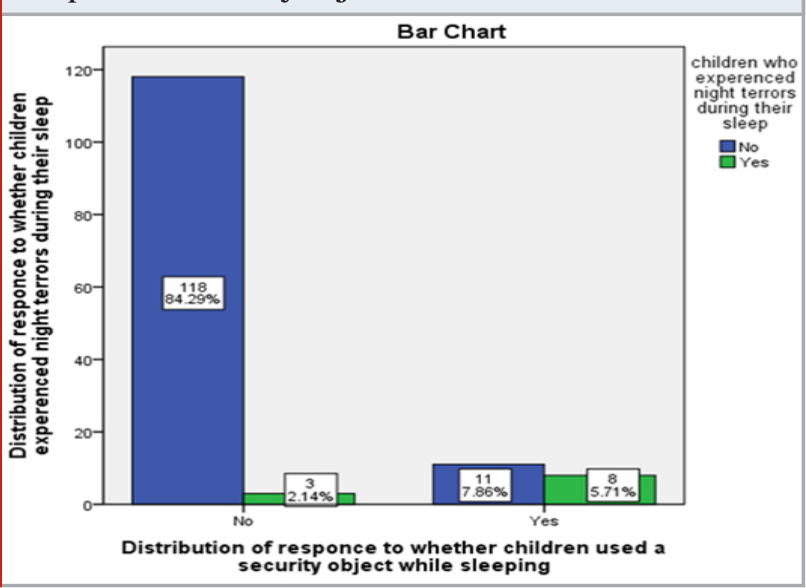

The frequency of behavioral insomnia in children, including insomnia and night walking, was 15\% in school-age children (Morgenthaler et al., 2006) (Johnson et al., 2006)and the prevalence of insomnia in adolescents between 16 and 18 years old was approximately 11\% (Kim, Lee and Ahn, 2017). These values are somewhat similar to the values obtained in this study.Sleeprelated breathing disorders are conditions that present problems in breathing during sleep and are caused by increased resistance in the upper respiratory tract. This includes snoring, upper airway resistance syndrome and obstructive sleep apnea (Li et al., 2010). The risk factors of habitual snoring are similar to those of SDB. In a study targeting elementary school children in China30), risk factors, such as low family income, lack of higher education in the father, breastfeeding for less than 6 months, smoking during pregnancy, obesity, overweight, respiratory problems (rhinitis, asthma, adenoids hypertrophy, chronic otitis media), and a family history of habitual snoring were investigated. In this study, however, such risks were not examined (Meltzer et al., 2010). Meltzer et al reported that the prevalence of sleep problems according to the ICD-9 (International Classification of Diseases, 9 th revision) is 3.7\%, which was lower than the results of previous studies.

Low prevalence is thought to be a result of the study having been conducted retrospectively based on medical records. The lack of interest in addressing sleep problems has been studied in previous research that indicated that while $24.6 \%$ of patients suffer from sleep problems, only 
4.1\% of parents discussed the problems and only 7.9\% of parents consulted a doctor. A systematic review found that traumatic childhood experiences (such as family conflict or sexual trauma) significantly increases the risk for a number of sleep disorders in adulthood, including sleep apnea, narcolepsy, and insomnia ((Kajeepeta et al., 2015) . The National Sleep Foundation found that high school students who reported insufficient sleep or daytime sleepiness also reported depressed mood and lower grades, whereas $80 \%$ of students who reported getting enough sleep made As and Bs in school.

\section{CONCLUSION}

Within the limitations of the present study, it was noted that the most common sleep disorder was sleep talking. It wad also noted that children who had the tendency of snoring also had the tendency of sleep talking and children who experienced night terrors had the habit of going to sleep with a security object.

Conflict of Interest: The author would like to declare there was no conflict of interest

\section{ACKNOWLEDGEMENTS}

I would like to thank my esteemed institution for providing me with the opportunity to do this study and would also like to thank my guide for her expert advice and encouragement which helped me with the completion of this study.

\section{REFERENCES}

Bhate, K. and Williams, H. C. (2013) 'Epidemiology of acne vulgaris', The British journal of dermatology, 168(3), pp. 474-485.

Chokroverty, S. (2010) 'Overview of sleep \& sleep disorders', The Indian journal of medical research, 131, pp. 126-140.

Cho, S. J. et al. (2002) 'The Prevalence and Associated Factors of Constipation in the School-aged Children', Korean Journal of Pediatric Gastroenterology and Nutrition, p. 26. doi: 10.5223/kjpgn.2002.5.1.26.

Durmer, J. S. and Dinges, D. F. (2005) 'Neurocognitive consequences of sleep deprivation', Seminars in neurology, 25(1), pp. 117-129.

Gokul, G. (2016) 'Common sleep disorders faced by adolescents', Research Journal of Pharmacy and Technology. A \& V Publications, 9(10), pp. 18021805.

Govindaraju, L., Jeevanandan, G. and Subramanian, E. M. G. (2017a) 'Comparison of quality of obturation and instrumentation time using hand files and two rotary file systems in primary molars: A single-blinded randomized controlled trial', European journal of dentistry, 11(3), pp. 376-379.

Govindaraju, L., Jeevanandan, G. and Subramanian,
E. M. G. (2017b) 'Knowledge and practice of rotary instrumentation in primary teeth among indian dentists: A questionnaire survey', Journal of International Oral Health, 9(2), p. 45.

Jeevanandan, G., Ganesh, S. and Arthilakshmi (2019) 'Kedo file system for root canal preparation in primary teeth', Indian journal of dental research: official publication of Indian Society for Dental Research, 30(4), pp. 622-624.

Jeevanandan, G. and Govindaraju, L. (2018) 'Clinical comparison of Kedo-S paediatric rotary files vs manual instrumentation for root canal preparation in primary molars: a double blinded randomised clinical trial', European archives of paediatric dentistry: official journal of the European Academy of Paediatric Dentistry, 19(4), pp. 273-278.

Jochebed, S. R. and Priya, A. J. (2015) 'Common sleep disorders in adolescents-A survey', Research journal of pharmaceutical, biological and chemical sciences. Journal of Pharmaceutical Sciences and Research, 7(6), p. 381.

Johnson, E. O. et al. (2006) 'Epidemiology of DSM-IV insomnia in adolescence: lifetime prevalence, chronicity, and an emergent gender difference', Pediatrics, 117(2), pp. e247-56.

Kajeepeta, S. et al. (2015) 'Adverse childhood experiences are associated with adult sleep disorders: a systematic review', Sleep Medicine, pp. 320-330. doi: 10.1016/j. sleep.2014.12.013.

Kamphuis, J. et al. (2012) 'Poor sleep as a potential causal factor in aggression and violence', Sleep medicine, 13(4), pp. 327-334.

Kim, D. S., Lee, C. L. and Ahn, Y. M. (2017) 'Sleep problems in children and adolescents at pediatric clinics', Korean journal of pediatrics, 60(5), pp. 158165.

Kim, W. B. and Kim, K. D. (1998) 'The epidemiology of childhood enuresis in Seoul and Kyunggi province', Korean journal of urology, 39(12), pp. 1166-1170.

Krakowski, A. C., Eichenfield, L. F. and Dohil, M. A. (2008) 'Management of atopic dermatitis in the pediatric population', Pediatrics, 122(4), pp. 812-824.

Li, S. et al. (2010) 'Habitual snoring in school-aged children: environmental and biological predictors', Respiratory research, 11, p. 144.

Meltzer, L. J. et al. (2010) 'Prevalence of diagnosed sleep disorders in pediatric primary care practices', Pediatrics, 125(6), pp. e1410-8.

Mindell, J. A. and Owens, J. A. (2015) A clinical guide to pediatric sleep: diagnosis and management of sleep problems. Lippincott Williams \& Wilkins.

Morgenthaler, T. I. et al. (2006) 'Practice parameters for behavioral treatment of bedtime problems and night 
wakings in infants and young children', Sleep, 29(10), pp. 1277-1281.

Nair, M. et al. (2018) 'Comparative evaluation of postoperative pain after pulpectomy with k-files, kedo-s files and mtwo files in deciduous molars -a randomized clinical trial', Brazilian Dental Science, 21(4), p. 411. Owens, J. (2005) 'Epidemiology of Sleep Disorders during Childhood', Principles and Practice of Pediatric Sleep Medicine, pp. 27-33. doi: 10.1016/b978-0-72169458-0.50008-8.

Owens, J. A. et al. (2000) 'Sleep habits and sleep disturbance in elementary school-aged children', Journal of developmental and behavioral pediatrics: JDBP, 21(1), pp. 27-36.

Panchal, V., Gurunathan, D. and Shanmugaavel, A. K. (2017) 'Smartphone application as an aid in determination of caries risk and prevention: A pilot study', European journal of dentistry, 11(4), pp. 469474.

Panchal, V., Jeevanandan, G. and Subramanian, E. (2019) 'Comparison of instrumentation time and obturation quality between hand $\mathrm{K}$-file, H-files, and rotary Kedo-S in root canal treatment of primary teeth: A randomized controlled trial', Journal of the Indian Society of Pedodontics and Preventive Dentistry, 37(1), pp. 75-79.

Panchal, V., Jeevanandan, G. and Subramanian, E. M. G. (2019) 'Comparison of post-operative pain after root canal instrumentation with hand $\mathrm{K}$-files, H-files and rotary Kedo-S files in primary teeth: a randomised clinical trial', European archives of paediatric dentistry: official journal of the European Academy of Paediatric Dentistry, 20(5), pp. 467-472.

Ramadurai, N. et al. (2019) 'Effectiveness of 2\% Articaine as an anesthetic agent in children: randomized controlled trial', Clinical oral investigations, 23(9), pp. 3543-3550.

Ramakrishnan, M., Dhanalakshmi, R. and Subramanian, E. M. G. (2019) 'Survival rate of different fixed posterior space maintainers used in Paediatric Dentistry - A systematic review', The Saudi dental journal, 31(2), pp. 165-172.

Ravikumar, D. et al. (2018) 'DNA profiling of Streptococcus mutans in children with and without black tooth stains: A polymerase chain reaction analysis', Dental research journal, 15(5), p. 334.

Ravikumar, D. et al. (2019) 'Evaluation of McNamara's analysis in South Indian (Tamil Nadu) children between 8-12 years of age using lateral cephalograms', Journal of oral biology and craniofacial research, 9(2), pp. 193-197.

Ravikumar, D., Jeevanandan, G. and Subramanian, E. M. G. (2017) 'Evaluation of knowledge among general dentists in treatment of traumatic injuries in primary teeth: A cross-sectional questionnaire study', European journal of dentistry, 11(2), pp. 232-237.

Ravindra, V. et al. (2018) 'A comparative evaluation between dermatoglyphic patterns and different terminal planes in primary dentition', Journal of clinical and experimental dentistry, 10(12), pp. e1149-e1154.

Ravindra, V. et al. (2019) 'A comparative evaluation between cheiloscopic patterns and the permanent molar relationships to predict the future malocclusions', Journal of clinical and experimental dentistry, 11(6), pp. e553-e557.

Samuel, S. R., Acharya, S. and Rao, J. C. (2020) 'School Interventions-based Prevention of Early-Childhood Caries among 3-5-year-old children from very low socioeconomic status: Two-year randomized trial', Journal of public health dentistry, 80(1), pp. 51-60.

Seo, W.-S. et al. (2008) 'Preliminary study of children's sleep problems in an elementary school in Daegu', Journal of the Korean Academy of Child and Adolescent Psychiatry. Korean Academy of Child and Adolescent Psychiatry, 19(3), pp. 156-161.

Subramanyam, D. et al. (2018) 'Comparative evaluation of salivary malondialdehyde levels as a marker of lipid peroxidation in early childhood caries', European journal of dentistry, 12(1), pp. 67-70.

Vignesh, R. et al. (2019) 'Management of Complicated Crown-Root Fracture by Extra-Oral Fragment Reattachment and Intentional Reimplantation with 2 Years Review', Contemporary clinical dentistry, 10(2), pp. 397-401.

Vishnu Prasad, S. et al. (2018) 'Report on oral health status and treatment needs of 5-15 years old children with sensory deficits in Chennai, India', Special care in dentistry: official publication of the American Association of Hospital Dentists, the Academy of Dentistry for the Handicapped, and the American Society for Geriatric Dentistry, 38(1), pp. 58-59. 